\title{
Risk assessment of agricultural drought using the CERES-Wheat model: a case study of Henan Plain, China
}

\author{
Haiyan Zhao ${ }^{1}$, Ge Gao ${ }^{2, *}$, Xiaodong Yan ${ }^{3,4}$, Qiang Zhang ${ }^{5}$, Meiting Hou ${ }^{6}$, Yeyu Zhu ${ }^{7}$, \\ Zhan Tian ${ }^{8}$ \\ ${ }^{1}$ Shanxi Climate Center, 80 Pingyang Street, 030006 Taiyuan, PR China \\ ${ }^{2}$ National Climate Center, China Meteorological Administration, 46 Zhongguancun South Street, 100081 Beijing, PR China \\ ${ }^{3}$ Key Laboratory of Regional Climate-Environment Research for Temperate East Asia, Institute of Atmospheric Physics, \\ Chinese Academy of Sciences, 40 Huayanli, 100029 Beijing, PR China \\ ${ }^{4}$ Beijing Normal University, 19 Xinjiekouwai Street, 100875 Beijing, PR China \\ ${ }^{5}$ China Meteorological Administration, 46 Zhongguancun South Street, 100081 Beijing, PR China, \\ ${ }^{6}$ China Meteorological Administration Training Centre, 46 Zhongguancun South Street, 100081 Beijing, PR China \\ ${ }^{7}$ Henan Climate Center, 110 Jinshui Road, 450003 Zhengzhou, PR China \\ ${ }^{8}$ Shanghai Climate Center, 166 Puxi Road, 200030 Shanghai, PR China
}

\begin{abstract}
Droughts caused by a lack of precipitation are one of the major factors limiting agricultural crop production. It is thus important to assess the risk of such droughts in order to reduce their effect on agriculture. In the present study, the drought risk for crop production was assessed through an integrated approach that analyzed the relationship between crop yield and drought on the Henan Plain, China. We used the calibrated CERES-Wheat model to simulate 2 levels of wheat yield, the yield potential and the water-limited yield potential, at 66 weather stations. The yield gap between the yield potential and the water-limited yield potential was used as an indicator of the effects of a precipitation deficit on crop production under rain-fed conditions. A strong linear relationship between the yield gap and the amount of precipitation in the growing season was observed for each station during the period 1962-2009. A uniform criterion for drought severity thresholds for the entire Henan Plain was constructed based on the yield gap. For each station, the growing-season precipitation thresholds associated with different drought severities were then calculated based on the linear relationship between the yield gap and the amount of precipitation in the growing season. Drought frequencies derived from changes in the amount of precipitation during the growing season were also examined for all stations and spatially interpolated over the plain. The results showed diverse spatial patterns of frequency with respect to different drought types. Light droughts often occurred in the southern region, and moderate droughts occurred more frequently in the western and eastern regions. Severe drought displayed a generally decreasing trend from north to south.
\end{abstract}

KEY WORDS: Crop model $\cdot$ Yield potential $\cdot$ Water-limited yield potential $\cdot$ Thresholds $\cdot$ Drought frequency

Resale or republication not permitted without written consent of the publisher

\section{INTRODUCTION}

Drought is one of the major limiting environmental factors for agricultural crop production in China. As one of the major crop-producing areas in China, the Henan Plain has always been threatened by such droughts. The frequency, intensity and duration of drought are expected to increase under global warming and will negatively affect global food security (Kim \& Byun 2009, Zheng et al. 2009). The effect of drought on wheat production is also being accelerated by climate change on the Henan Plain. There- 
fore, a risk assessment of agricultural drought is essential to improve drought preparedness and reduce the effects of drought on agriculture (Sun 2009).

There are many definitions of risk. In a broad sense, risk may be defined as the capacity of a system to suffer losses when exposed to an external stressor (Wisner et al. 2004, Iglesias \& Quiroga 2007). Similarly, there are many methods for risk assessment. For agricultural drought risk, crop yield is a reliable indicator because of the close relationship between crop yield and water stress (Kumar \& Panu 1997, Wu \& Wilhite 2004). Lobell et al. (2006) described the response of yields to climate change using observed yield data. Li et al. (2009) assessed the drought risk for world crop production by analyzing the correlation between historical crop yield and meteorological drought. However, the relationship between climate, crop growth and yield is complicated due to variability in climate, soil, soil tillage and crop management, among other factors (Wolf \& Van Diepen 1995). In particular, the observed historical crop yields can be affected by both climatic and socio-economic factors. Dynamic crop growth simulation models incorporating environmental factors with management operations quantitatively describe the processes of crop growth and can be used to predict crop yield. Crop growth simulation models are especially well suited to quantify the effects of climatic variables on crop yield (Alexandrov \& Hoogenboom 2000). Using crop model simulations, it is possible to study the relative role of precipitation in the crop production process while controlling for other important factors, such as temperature, nutrients and planting methods, which might otherwise overshadow the role of precipitation.

Here, we selected a dynamic crop simulation model called Crop Environment Resource Evaluation through Synthesis (CERES)-Wheat to simulate wheat yield. The CERES model has been widely used to analyze the responses of crop yields to climate change (Chipanshi et al. 1999). To explore the associations of yield trends and changes in precipitation, we used the calibrated CERES-Wheat model to export data on the yield potential and the water-limited yield potential. The yield gap $(\lambda)$ between the yield potential and the water-limited yield potential, i.e. the decrease in yield between the potential and water-limited scenarios, represents the effects of the water deficit on crop production and can be considered a proxy for the agricultural drought risk. The water-limited yield potential can be described as a linearly increasing function of precipitation in a specified range according to Harmsen (2000a), especially for rain-fed agriculture in semi-arid regions. Regression models have accordingly been applied in previous studies (Kaufmann \& Snell 1997, Lobell \& Asner 2003, Parry et al. 2004, Cabas et al. 2010) to estimate the influence of precipitation on wheat yield, and these studies provide a quantitative context for this work.

The purpose of the present study is to use the CERES-Wheat model to assess the drought risk for wheat on the Henan Plain, China. Drought risk assessment is primarily focused on the basis of the severity and frequency of droughts. In Section 2, we describe the data and methods used in this study. In Section 3, we summarize the calibration of the CERES-Wheat model and its validation by experimental measurements of phenological stages and crop yields. In Section 4, we first examine the spatial variability in $\lambda$ and the growing season precipitation (GSP) and confirm a linear relationship between $\lambda$ and GSP at each station. We then classify agricultural drought severity according to $\lambda$. Based on different measures of drought severity, the corresponding thresholds of GSP for each of the 66 stations were calculated. Finally, GSP values were used to derive the drought frequencies for the 66 stations and were spatially interpolated over the entire Henan Plain. In Section 5, we discuss the results and present our conclusions.

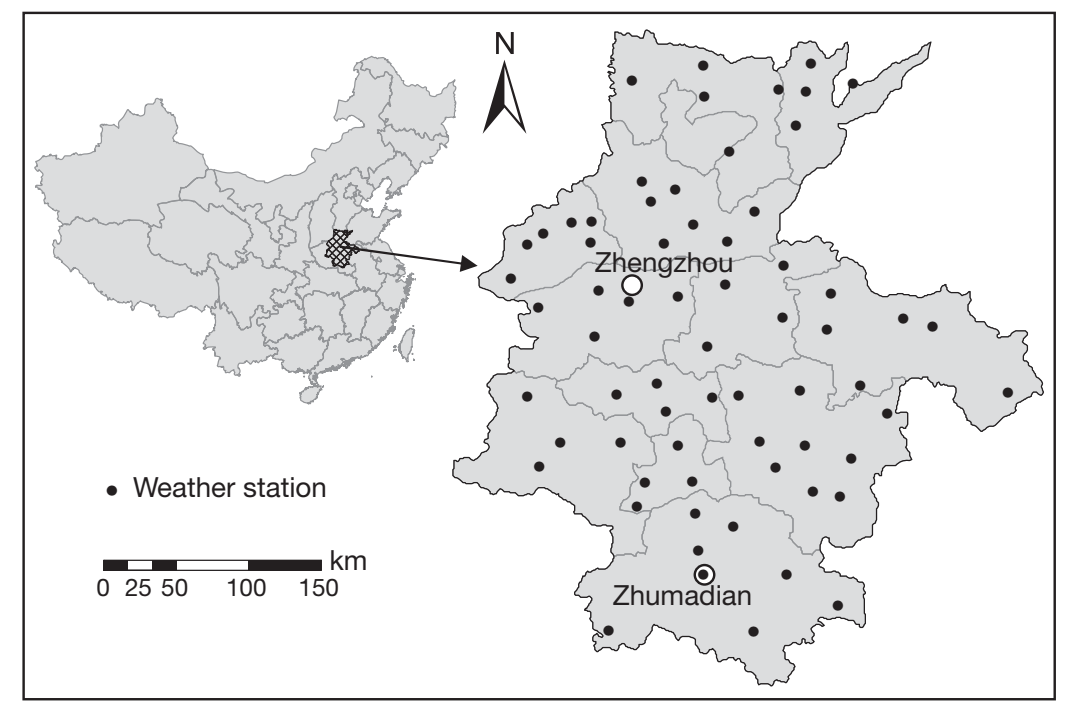

Fig. 1. Location of the Henan Plain in China, and spatial distribution of 66 weather stations on the Henan Plain 


\section{DATA AND METHODS}

\subsection{Study area}

The Henan Plain, located in Henan Province along the middle and lower reaches of the Yellow River, is one of the agriculturally most productive areas in China (Fig. 1). The Henan Plain has a monsoonal climate in the temperate zone. The winter-wheat and summer-maize rotation system, which fills the whole year, is the major agricultural production system on the plain (He et al. 2009).

The mean annual rainfall on Henan Plain is approximately 570 to $1100 \mathrm{~mm}$, and nearly $70 \%$ of the total rainfall occurs between June and September. Hence, droughts occur more frequently in the winter-spring season than in the summer-autumn season. Recent climate change has affected the availability of water to crops on the Henan Plain. Supplemental irrigation is now required to support the growth of winter wheat (Zhang et al. 2003).

\subsection{The CERES-Wheat model}

The CERES-Wheat model (Ritchie \& Otter 1985) under the Decision Support System for Agrotechnology Transfer (DSSAT) shell can simulate the effects of changes in the environment and management on wheat growth, development and yield (Godwin et al. 1990). The model has been successfully applied in many regions of the world. For example, Chipanshi et al. (1999) have used this model to simulate the effect of drought on wheat yields on a large scale in a semi-arid region. Using the CERES model, Popova \& Kercheva (2005) evaluated the risks of heavy precipitation and drought in the region around Sofia.

The inputs required by the CERES-Wheat model generally include daily weather data (solar radiation, maximum and minimum temperatures and precipitation), soil data, crop management data and genetic coefficients (Tsuji et al. 1994).

In the present study, we defined the wheat growing season as the period from October 15 to the date of maturity simulated by the model, with GSP indicating the total precipitation in the same period. Daily weather data were derived from the China National Meteorological Information Center (CNMC) and had been subjected to quality control by the CNMC (Zhai et al. 2005). There are approximately 90 weather stations at the county level on the Henan Plain, but not all stations have continuous weather data records for the study period (1962-2009). To ensure continuous and complete data records, we selected a total of 66 weather stations (also shown in Fig. 1) after dropping the stations with missing values for the period 1962-2009.

Soil information was derived from soil survey data (National Soil Survey Office 1995). Crop management data were derived from field experimental data provided by the National Meteorological Information Center of China. Genetic coefficients were determined using the GENCALC software of DSSAT V.3.5 (Singh et al. 2008).

\subsection{The yield potential and water-limited yield potential}

The yield potential $\left(Y_{\mathrm{P}}\right)$ can be defined as the highest possible yield that can be obtained under ideal management and with an unlimited supply of water and nutrients (Dobermann et al. 2003). In a given growth environment, the $Y_{\mathrm{P}}$, which is solely determined by crop characteristics, solar radiation and temperature, is regarded as the theoretical upper limit of crop productivity (Cao et al. 1995). The waterlimited yield potential $\left(Y_{\mathrm{W}}\right)$ is determined by crop characteristics, solar radiation, temperature and water availability. In the present study, the $Y_{\mathrm{W}}$ means the yield under rain-fed conditions.

After the CERES-Wheat model was calibrated and validated, simulations were performed to reflect these 2 levels of wheat yield: the $Y_{\mathrm{P}}$ and $Y_{\mathrm{W}}$. For each station, $\lambda(\%)$, which is the yield gap between the yield potential and the water-limited yield potential, in a given year can be expressed as:

$$
\lambda=\left[\left(Y_{\mathrm{P}}-Y_{\mathrm{W}}\right) / Y_{\mathrm{P}}\right] \times 100
$$

\subsection{Determination of the drought severity threshold}

To facilitate comparison of the spatial patterns of drought, we constructed a uniform criterion of drought severity thresholds for the entire plain. For a specified station, the mean value over 1962-2009 $\left(\lambda^{\prime}\right)$ of $\lambda$ was calculated. Then, based on each $\lambda^{\prime}$ for all 66 stations, $\lambda_{\text {mean }}^{\prime}$ and $\sigma \lambda^{\prime}$ were calculated, where $\lambda_{\text {mean }}^{\prime}$ represents the mean $\lambda^{\prime}$ for all 66 stations and $\sigma \lambda^{\prime}$ represents the standard deviation of $\lambda^{\prime}$ for 66 stations.

Using $\lambda_{\text {mean }}^{\prime}$ and $\sigma \lambda^{\prime}$, we classified the agriculture drought severity for a specified station in a given year as light, moderate, or severe. The $\lambda$ thresholds for drought severity classes were set to: (1) light 
drought $\left(\lambda_{\text {mean }}^{\prime}-\sigma \lambda^{\prime} \leq \lambda<\lambda_{\text {mean }}^{\prime}\right)$, (2) moderate drought $\left(\lambda_{\text {mean }}^{\prime} \leq \lambda<\lambda_{\text {mean }}^{\prime}+\sigma \lambda^{\prime}\right)$ and (3) severe drought $\left(\lambda \geq \lambda_{\text {mean }}^{\prime}+\sigma \lambda^{\prime}\right)$.

\subsection{Drought frequency analysis}

The relation between the $\lambda$ and GSP for a given station under rain-fed conditions can be approximated as:

$$
\lambda=a P+b
$$

or

$$
P=\frac{\lambda-b}{a}
$$

where $a$ is a water-dependent activity coefficient, $P$ is the amount of GSP and $b$ is the intercept. Notably, Eqs. (2) and (3) are only valid for a limited range of rainfall (Harmsen 2000b).

Using $\lambda$ and GSP data for each station, we obtained the fitted values of the parameters $a$ and $b$ following Eq. (2). Based on different $\lambda$ thresholds, the GSP thresholds associated with different drought severities were then calculated for each station following Eq. (3). Drought frequency was then computed as the ratio of the number of years with GSP within the different GSP threshold ranges to the total length of the study period (48 yr).

\section{CALIBRATION AND VALIDATION OF THE CERES-WHEAT MODEL}

The CERES-Wheat model was calibrated and validated by comparing simulated phenological stages and crop yields to parallel field experiments performed from 1981 to 1999 at 2 experimental stations located in the central-northern (Zhengzhou) and southern regions (Zhumadian) of Henan Plain as shown in Fig. 1.

The genetic parameters of the CERES-Wheat model were calibrated in order to minimize the difference between the observed and corresponding simulated data. Based on the GENCALC software of DSSAT V.3.5, we derived the 7 genetic coefficients (presented in Table 1) of the wheat variety YUMAI 18. After obtaining the genetic parameters, the CERES-Wheat model was validated by comparing simulations with observed data. Fig. 2 shows the regression of the simulated versus observed flowering dates, maturity dates and yields at the 2 experimental stations. The results showed good agreement between these simulated and observed parameters.
Table 1. Genetic coefficients derived using the CERESWheat model

\begin{tabular}{|lcr|}
\hline Description & Name & Value \\
\hline Vernalization coefficient & P1V & 6.0 \\
Photoperiod coefficient & P1D & 0.5 \\
Relative grain filling duration & P5 & -5.0 \\
Kernel number per unit weight of stem & G1 & 4.9 \\
Optimal kernel filling rate & G2 & 70.0 \\
Non-stressed dry stem weight & G3 & 4.4 \\
The interval in thermal time between & PHINT & 80.0 \\
successive leaf tip appearance & & \\
\hline
\end{tabular}

The correlation coefficients were always significant at the 0.001 level, and the adjusted $\mathrm{r}^{2}$ values (coefficient of determination) ranged from 0.66 to 0.978 . The departures between the simulated and observed flowering and maturity dates were generally $<1 \mathrm{wk}$ at the 2 stations. The simulated yields were quite close to the observed yields, with the difference between them ranging from -11.3 to $8.5 \%$.

\section{AGRICULTURAL DROUGHT RISK ASSESSMENT}

\subsection{Spatial variability of GSP and $\lambda$}

Fig. 3 shows the latitudinal distribution of the average GSP during the wheat-growing season on the Henan Plain for the study period. The GSP decreased from south to north. In the south, the GSP generally ranged from 270 to $390 \mathrm{~mm}$. In the central area, the GSP normally varied from 210 to $270 \mathrm{~mm}$, and it was typically $<210 \mathrm{~mm}$ in the northeast. The rainfall was not sufficient to support winter-wheat production over the whole plain, as winter wheat requires approximately 430 to $470 \mathrm{~mm}$ of water per year (Zhang et al. 2003).

The coefficient of variation (CV) of the GSP during the wheat-growing season increased from south to north (Fig. 3b). Fig. 3 shows that the largest variation in GSP occurred in the northeast, which was also associated with the lowest amounts of GSP. This pattern suggests that extreme precipitation events sometimes occurred in the northeast.

The yield potential and water-limited yield potential were modeled at 66 weather stations on the Henan Plain for the period 1962-2009. The mean values of $\lambda$ and the CV of $\lambda$ were obtained following Eq. (1). The mean $\lambda$ and the CV of $\lambda$ at the 66 stations were then interpolated for the entire plain (Fig. 4). The mean $\lambda$ ranged from 52 to $61 \%$ in the northern region, but it 

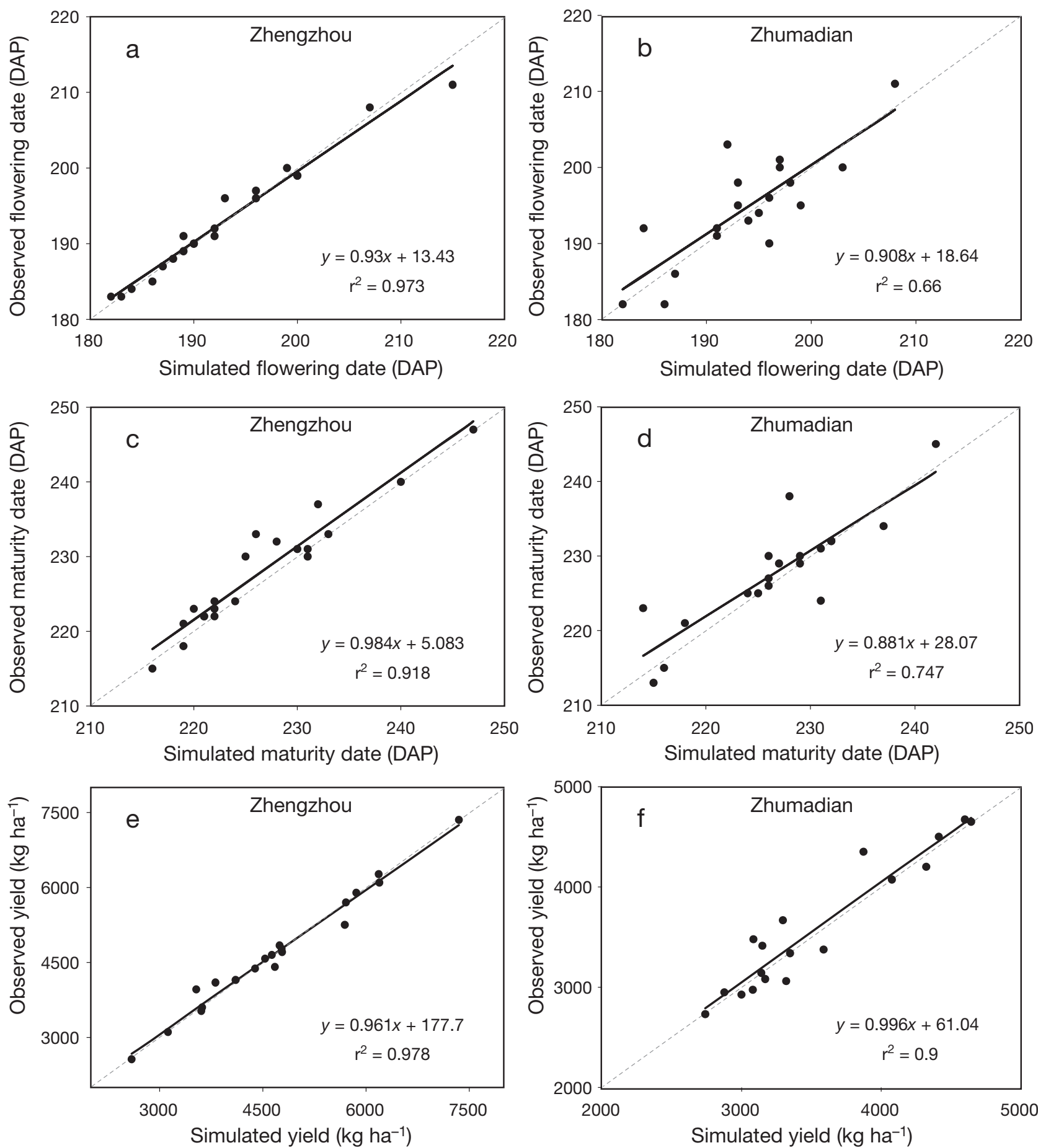

Fig. 2. Comparisons of the simulated and observed flowering dates (days after planting, DAP), maturity dates (DAP) and yields of winter wheat at the Zhengzhou (a, c, e) and Zhumadian (b, d, f) experimental stations between 1981 and 1999 . The dashed line represents a 1:1 relationship

was $<52 \%$ in almost all of the central and southern regions (Fig. 4a), which suggested that rainfall was relatively more suitable for winter wheat in the middle and southern areas of the Henan Plain. However, yield loss due to water deficit was probably serious in the southern region in some years because the $\mathrm{CV}$ of $\lambda$ was higher than for other regions (Fig. 4b).

Regions with low CV values of $\lambda$ (Fig. 4b) generally correspond to those regions with high values of $\lambda$ (Fig. 4a), which indicates the rainfall available to 


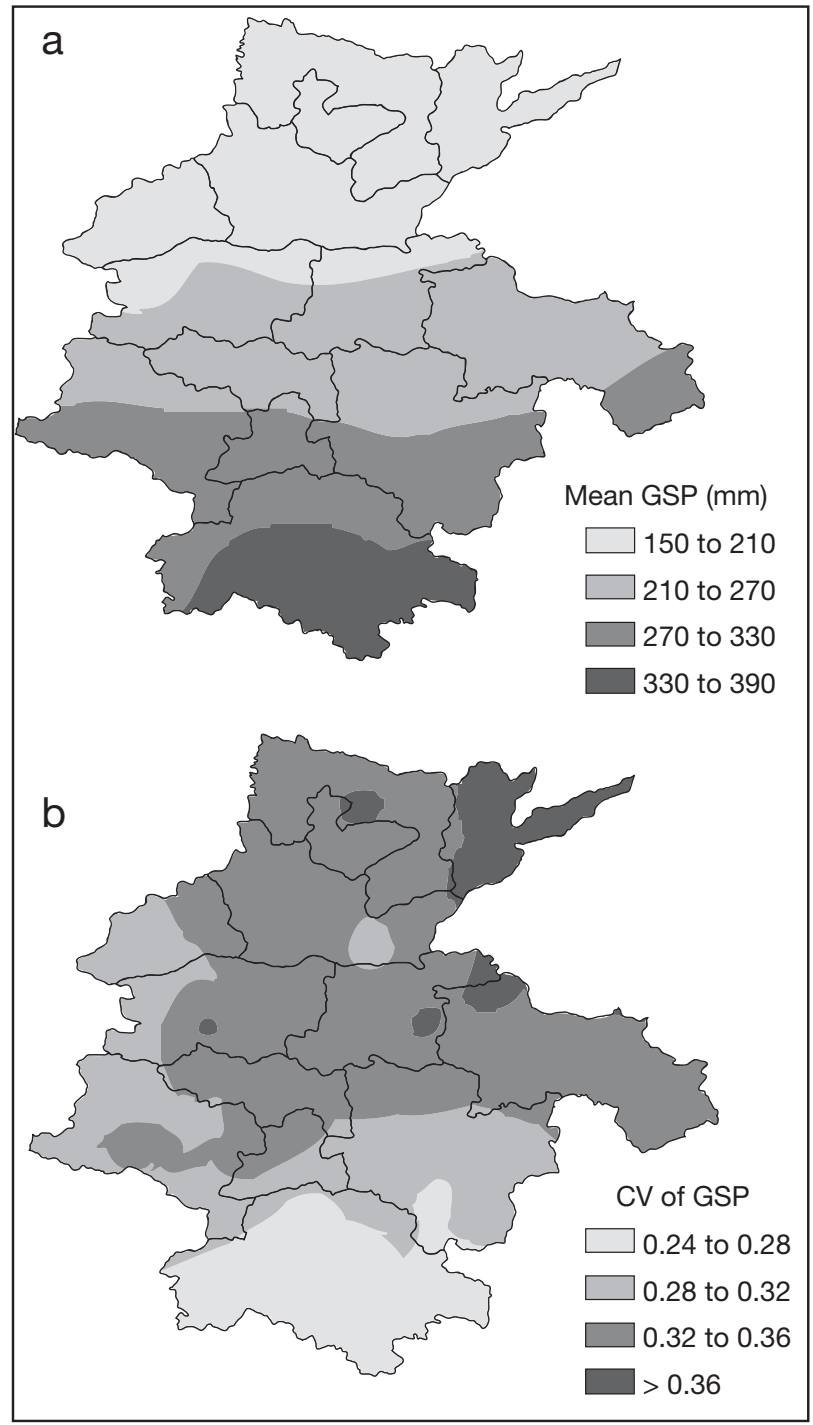

Fig. 3. Spatial patterns of the average values (a) and coefficients of variation (CV) (b) of the growing season precipitation (GSP)

crops in those regions consistently represented the worst situation on the Henan Plain.

\subsection{The relationship between GSP and $\lambda$}

Point correlation coefficients of GSP and $\lambda$ for each station are shown in Fig. 5a. There were statistically significant negative correlations between GSP and $\lambda$ for all stations at the 0.01 significance level.

Regression analysis was then performed between GSP and $\lambda$ for all stations. The slopes of the regression lines for the central and northeastern stations were steeper than for other stations (Fig. 5b), suggesting that the GSP probably played a more important

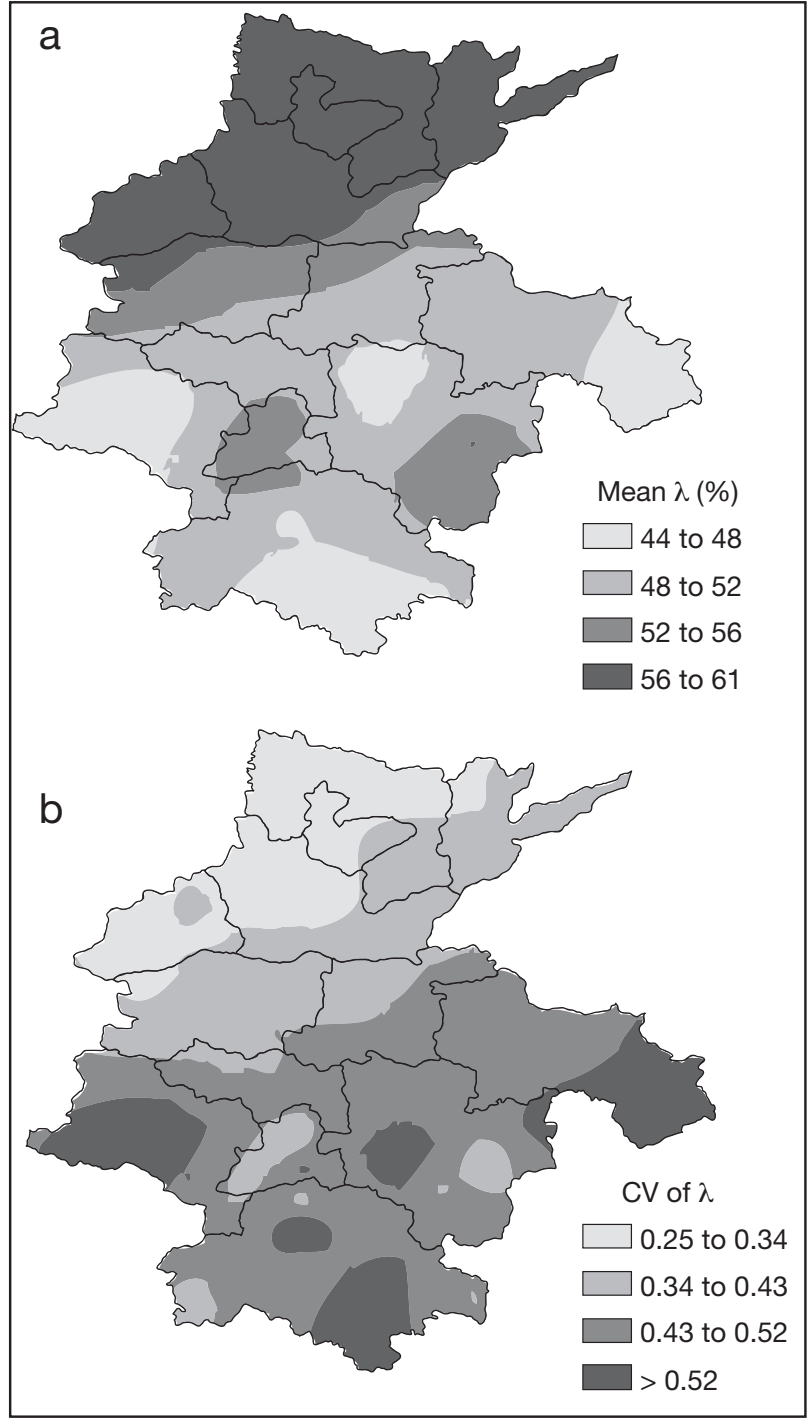

Fig. 4. Spatial patterns of the average values (a) and coefficients of variation $(\mathrm{CV})(\mathrm{b})$ of the yield gap $(\lambda$, see Section 1$)$

role in controlling winter-wheat production in the central and northeast regions.

\subsection{Spatial variability of drought frequency}

According to the drought classification criteria described in Section 2.4, the drought severity thresholds for the entire plain were: (1) light drought (46.6 $\leq$ $\lambda<53.5)$, (2) moderate drought $(53.5 \leq \lambda<60.4)$ and (3) severe drought $(\lambda \geq 60.4)$. Using these thresholds of $\lambda$ and Eq. (3), we calculated the corresponding thresholds of GSP for each of the 66 stations. Point data of the GSP thresholds were then spatially interpolated (Fig. 6). 


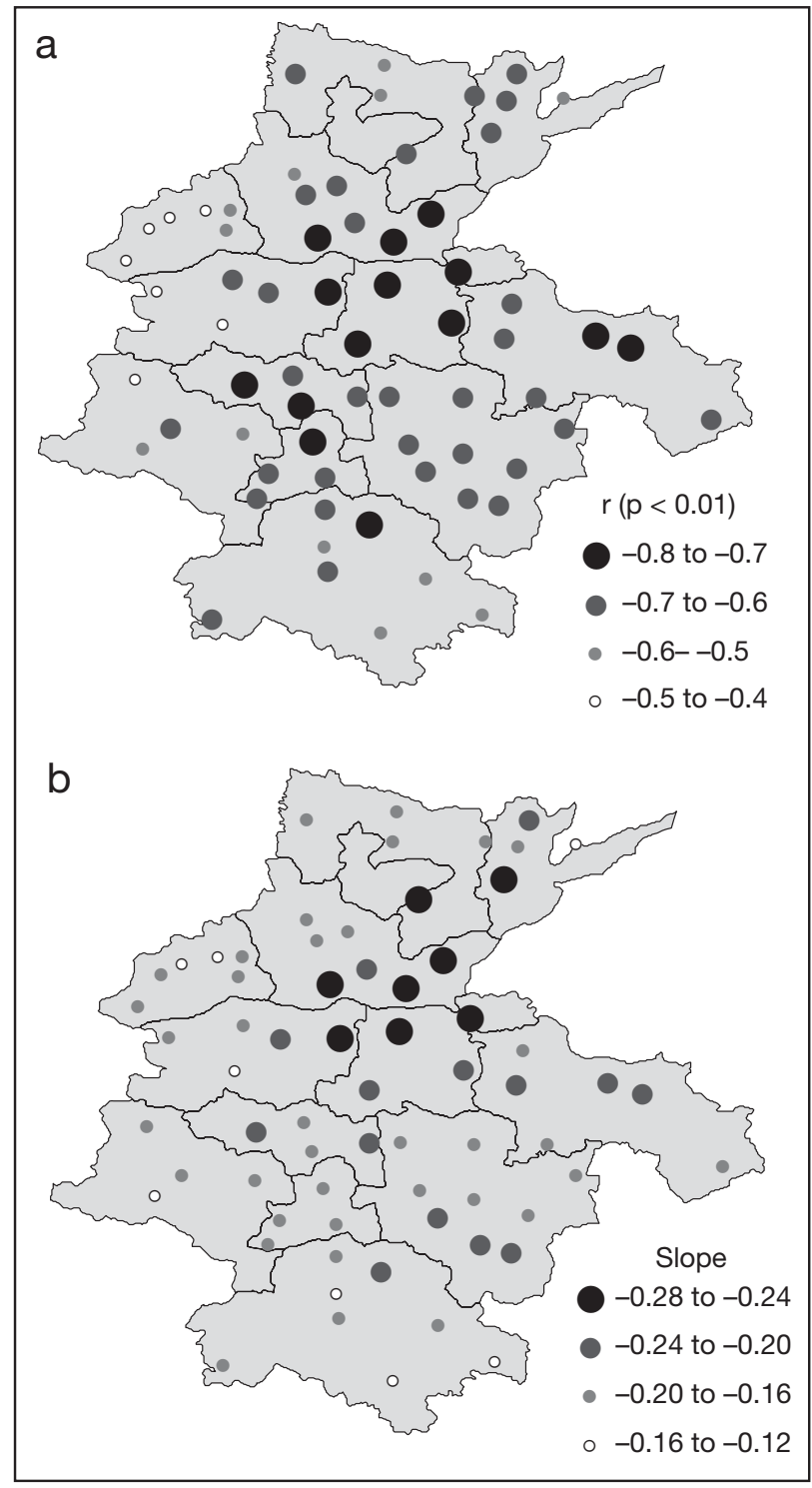

Fig. 5. Correlation coefficients (a) and the slopes of regression lines (b) between growing season precipitation and $\lambda$ at 66 stations on the Henan Plain for the period 1962-2009

Fig. 6 shows a generally increasing north-south gradient of the GSP thresholds. There were no significant differences in spatial patterns of the GSP thresholds for light, moderate, or severe drought. However, 3 types of drought had different GSP threshold ranges. GSP threshold ranges for light (Fig. 6a), moderate (Fig. 6b) and severe drought (Fig. 6c) were $220-380 \mathrm{~mm}, 200-320 \mathrm{~mm}$ and 0-278 $\mathrm{mm}$, respectively. The GSP thresholds emphasize the role of precipitation in conjunction with other factors (e.g. temperature and soil) in yield production. Relatively more water is required to prevent drought and

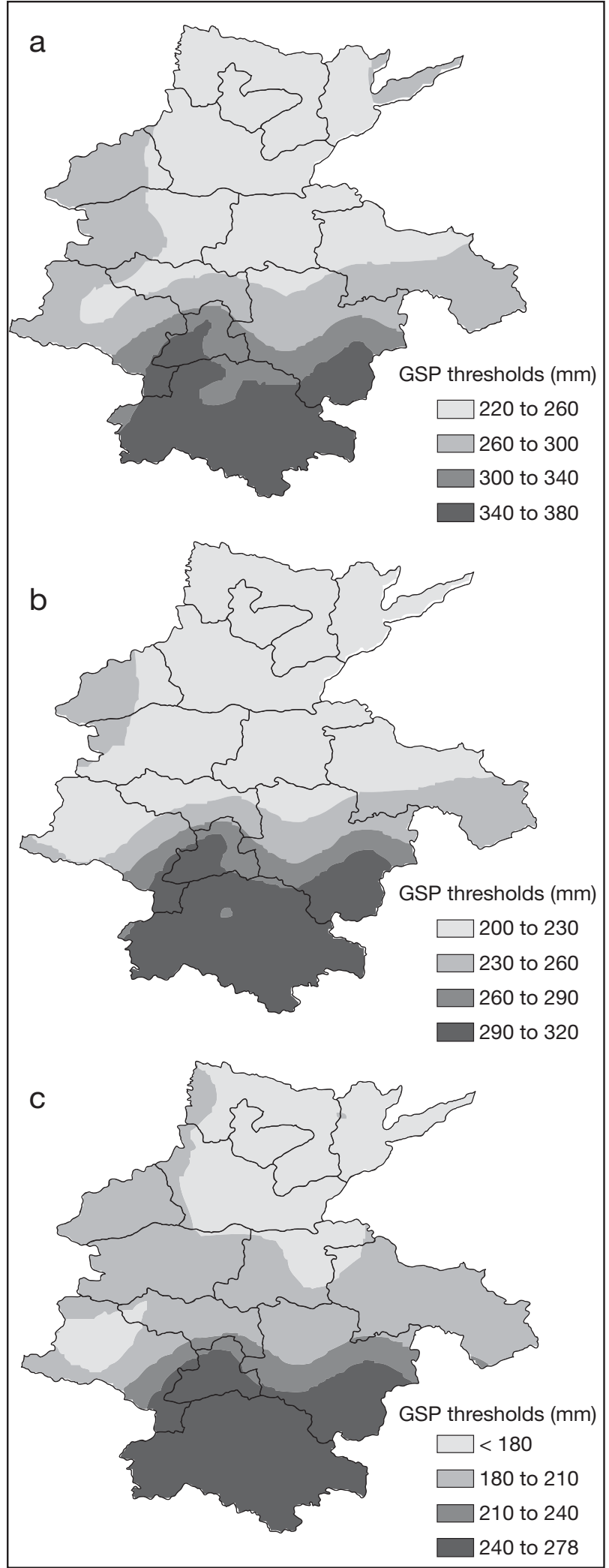

Fig. 6. Spatial variation in the growing season precipitation (GSP) thresholds associated with different levels of drought severity: (a) light, (b) moderate and (c) severe 
support crop production in regions with higher GSP thresholds.

Using the methods described in Section 2.4, the drought frequencies were examined for 66 stations and spatially interpolated (Fig. 7). The frequencies of occurrence of light drought were $<20 \%$ and were relatively highly concentrated in the south. The frequencies of moderate drought were $<23 \%$ and occurred relatively frequently in the west and east. Severe drought occurred more frequently, with an approximately decreasing pattern of frequency from north to south.

\section{DISCUSSION AND CONCLUSIONS}

Using the CERES-Wheat model, we performed a drought risk assessment for winter wheat on the Henan Plain of China. After the model was calibrated and validated, the yield potential and water-limited yield potential were simulated using data from 66 weather stations on the Henan Plain during the period 1962-2009. The yield gap between the yield potential and the water-limited yield potential was used as a proxy to assess the effect of drought on winter-wheat yields.

The multi-year averages of $\lambda$ ranged from 52 to $61 \%$ in the northern region, but were $<52 \%$ in the central and southern regions. The rainfall available during the wheat-growing season in the northern region, which had high values of $\lambda$, usually represented the worst situation for wheat production on the Henan Plain. There was a general trend of increasing GSP from north to south. Extreme precipitation events appeared to be potentially more frequent in the northeast than in other regions. A significant linear relationship between $\lambda$ and GSP was observed at a confidence level of 0.99 at each station. The GSP probably plays a relatively more important role in affecting winter-wheat yields in the central and northeast region than on the rest of the plain.

The severity of agricultural drought for each station was evaluated and classified as light, moderate, or severe based on uniform thresholds derived from the values of $\lambda$. Using different drought severities and the fitted linear regressions between $\lambda$ and GSP, we calculated the corresponding thresholds of GSP for each station. The drought frequencies were then examined at each station and spatially interpolated over the whole plain. Relatively high frequencies of light droughts occurred in the southern region, and high frequencies of moderate droughts occurred in the western and eastern regions. Severe drought fre-

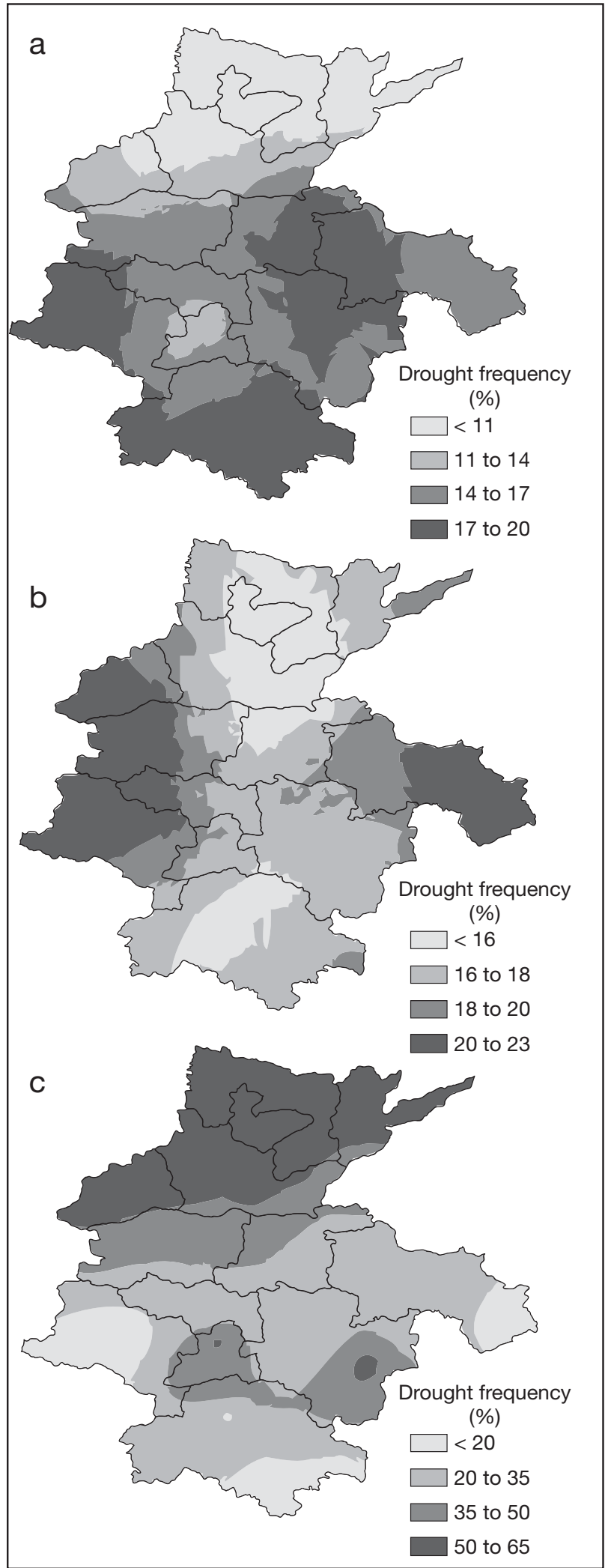

Fig. 7. Spatial variation in drought frequency according to different growing season precipitation thresholds: (a) light drought, (b) moderate drought and (c) severe drought 
quencies displayed a generally decreasing trend from north to south.

In the present study, calibration and validation of the CERES-Wheat model were based on linear regression, which is probably not entirely satisfactory for model evaluation (Kobayashi \& Salam 2000). However, the timing of phenological events simulated by the model was, in general, similar to our experimental observations.

The yield gap between the yield potential and the water-limited yield potential simulated by the CERES-Wheat model can reveal the influence of precipitation on crop yield, whereas conventional field experiments are limited by confounding factors (Pathak et al. 2003). However, the water-limited yield potential only represents the yield under rain-fed conditions. In fact, many types of irrigation equipment are used in the northern and eastern regions of the Henan Plain, where the ratio of irrigated land has increased to $60 \%$ in recent years. Therefore, risk frequency based on yield gap represents the effect of meteorological drought on agriculture.

For the entire study region, we used the relationship between the mean yield and the standard deviation of the yield to establish a criterion for drought severity. This criterion might be considered relatively arbitrary, though yield losses have been used to classify types of agricultural drought risk in a previous study (Karim \& Iqbal 2001).

The precipitation thresholds representing different drought severities derive directly from the function relating the thresholds to the yield gap. Thus, drought risk assessment can be made operationally practical by simply comparing the actual precipitation data with precipitation thresholds. The spatial distribution of drought frequencies obtained in this study may be useful for identifying vulnerable and emergent regions and improving the management of droughts in the study area.

Acknowledgements. The authors acknowledge financial support from the following projects: the National Key Technology Research and Development Program (Grant No. 2007BAC29B02) and the Special Fund for Public Welfare Industry (Meteorology, Grant No. GYHY200906019).

\section{LITERATURE CITED}

Alexandrov VA, Hoogenboom G (2000) The impact of climate variability and change on major crops in Bulgaria. Agric Meteorol 104:315-327

> Cabas J, Weersink A, Olale E (2010) Crop yield response to economic, site and climatic variables. Clim Change 101: $599-616$
Cao MK, Ma SJ, Han CR (1995) Potential productivity and human carrying capacity of an agro-ecosystem: an analysis of food production potential of China. Agric Syst 47: $387-414$

> Chipanshi AC, Ripley EA, Lawford RG (1999) Large-scale simulation of wheat yields in a semi-arid environment using a crop-growth model. Agric Syst 59:57-66

Dobermann AR, Arkebauer TG, Cassman KG, Drijber RA, Specht JE and others (2003) Understanding corn yield potential in different environments. In: Murphy LS (ed) Fluid focus: the third decade. Proceedings of the 2003 Fluid Forum, Vol 20. Fluid Fertilizer Foundation, Manhattan, KS, p 67-82

Godwin D, Ritchie JT, Singh U, Hunt L (1990) A user's guide to CERES-Wheat V2.10. International Fertilizer Development Center, Muscle Shoals, AL

Harmsen K (2000a) A modified Mitscherlich equation for rainfed crop production in semi-arid areas. 1. Theory. Neth J Agric Sci 48:237-250

Harmsen K (2000b) A modified Mitscherlich equation for rainfed crop production in semi-arid areas. 2. Case study of cereals in Syria. Neth J Agric Sci 48:251-272

He P, Li ST, Jin JY, Wang HT, Li CJ, Wang YL, Cui RZ (2009) Performance of an optimized nutrient management system for double-cropped wheat-maize rotations in NorthCentral China. Agron J 101:1489-1496

> Iglesias A, Quiroga S (2007) Measuring the risk of climate variability to cereal production at five sites in Spain. Clim Res 34:47-57

Karim Z, Iqbal MA (2001) Impact of land degradation in Bangladesh: changing scenario in agricultural land use. Bangladesh Agricultural Research Center (BARC), Dhaka

Kaufmann RK, Snell SE (1997) A biophysical model of corn yield: integrating climatic and social determinants. Am J Agric Econ 79:178-190

Kim DW, Byun HR (2009) Future pattern of Asian drought under global warming scenario. Theor Appl Climatol 98: $137-150$

Kobayashi K, Salam MU (2000) Comparing simulated and measured values using mean squared deviation and its components. Agron J 92:345-352

- Kumar V, Panu U (1997) Predictive assessment of severity of agricultural droughts based on agro-climatic factors. J Am Water Resour Assoc 33:1255-1264

Li Y, Ye W, Wang M, Yan X (2009) Climate change and drought: a risk assessment of crop-yield impacts. Clim Res 39:31-46

> Lobell DB, Asner GP (2003) Climate and management contributions to recent trends in US agricultural yields. Science 299:1032

Lobell DB, Field CB, Cahill KN, Bonfils C (2006) Impact of future climate change on California perennial crop yields: model projections with climate and crop uncertainties. Agric Meteorol 141:208-218

National Soil Survey Office (1995) China soil series, Vol IV. Agricultural Press, Beijing (in Chinese)

> Parry MA, Rosenzweig C, Iglesias A, Livermore M, Fisher G (2004) Effects of climate change on global food production under SRES emissions and socio-economic scenarios. Glob Environ Change 14:53-67

> Pathak H, Ladha JK, Aggarwal PK, Peng S and others (2003) Trends of climatic potential and on-farm yields of rice and wheat in the Indo-Gangetic Plains. Field Crops Res 80:223-234

Popova Z, Kercheva M (2005) CERES model application for 
increasing preparedness to climate variability in agricultural planning - Risk analyses. Phys Chem Earth 30: $117-124$

Ritchie JT, Otter S (1985) Description and performance of CERES wheat: a user oriented wheat yield model. In ARS Wheat Yield Project. US Department of Agriculture, ARS 38:159-175

Singh AK, Tripathy R, Chopra UK (2008) Evaluation of CERES-Wheat and CropSyst models for water-nitrogen interactions in wheat crop. Agric Water Manage 95: 776-786

Sun S (2009) Blended drought indices for agricultural drought risk assessment on the Canadian prairies. Carleton University, Ottawa

Tsuji GY, Uehara G, Balas S (1994) A decision support system for agrotechnology transfer, DSSAT, V. 3, Vols 1, 2 and 3. University of Hawaii, Honolulu, HI

Wisner B, Blaikie P, Cannon T, Davis I (2004) At risk: natural

Submitted: February 28, 2011; Accepted: September 19, 2011 hazards, people's vulnerability and disasters. Routledge, Wiltshire

- Wolf J, Van Diepen CA (1995) Effects of climate change on grain maize yield potential in the European Community. Clim Change 29:299-331

Wu H, Wilhite DA (2004) An operational agricultural drought risk assessment model for Nebraska, USA. Nat Hazards 33:1-21

Zhai P, Zhang X, Wan H, Pan X (2005) Trends in total precipitation and frequency of daily precipitation extremes over China. J Clim 18:1096-1108

Zhang XY, Pei D, Hu CS (2003) Conserving groundwater for irrigation in the North China Plain. Irrig Sci 21:159-166

> Zheng H, Chen L, Han X, Zhao X, Ma Y (2009) Classification and regression tree (CART) for analysis of soybean yield variability among fields in Northeast China: the importance of phosphorus application rates under drought conditions. Agric Ecosyst Environ 132:98-105

Proofs received from author(s): November 10, 2011 